Brit. J. industr. Med., 1954, 11, 284.

\title{
A SIZE-SELECTING SAMPLER FOR AIRBORNE DUST
}

\author{
BY \\ B. M. WRIGHT \\ From the Pneumoconiosis Research Unit of the Medical Research Council, \\ Llandough Hospital, near Cardiff
}

(RECEIVED FOR PUBLICATION MAY 30, 1954)

It has long been known that airborne dust often differs markedly in composition from dust which has settled on the ground, and this in turn differs in composition from the parent substance from which the dust was produced.

This variation in composition is related to variation in particle size, and continues even within the size range of airborne dust. For instance, Drinker and Hatch (1936) quote an example where the free silica content of an airborne foundry dust varied from $72.3 \%$ for particles over $10 \mu$ in diameter, $28.2 \%$ between $5 \mu$ and $10 \mu, 22.7 \%$ between $2 \mu$ and $5 \mu$, down to only $3 \cdot 3 \%$ below $2 \mu$.

It has also been known for many years (McCrae, 1913; Watkins-Pitchford, 1916) that the dust retained in the lungs consists almost entirely of particles below about $7 \mu$ in average diameter. More recent theoretical and experimental studies (Findeisen, 1935 ; Davies, 1949) have shown that the failure of large particles to penetrate and be retained in the lungs is related to their high settling rate in air.

It is evident then that any chemical analysis of airborne dust which is to be relevant to pneumoconiosis must be confined to that fraction of the dust which consists of particles of what may be called for convenience " respirable" size. This conclusion has been recognized by a number of workers, and they have attempted to comply with it by separating the respirable fraction from the sample after collection, either by liquid sedimentation or by air elutriation. The former method is unsatisfactory since the different densities of the various ingredients will cause a greater difference in settling rate in liquid than in air. The method is, moreover, open to another objection, which also applies to air elutriation, namely that dust in the air is nearly always aggregated to some extent (Watson, 1949) and the aggregates will have a settling velocity very different from that of their constituent particles. If the dust is collected and then re-dispersed in liquid, it will be largely disaggregated, and even if re-dispersed in air its original state of aggregation will not be restored, so that it will not be separated into true respirable and non-respirable fractions.

Apart from these objections, the process of separation after collection is laborious and to be avoided if possible, but until recently no easy and satisfactory method of separation while sampling was available. The most obvious device, a vertical elutriator, such as is used commercially for air separation of powders (Haultain, 1937) can be shown to be impracticable owing to the very large size of chamber needed for the volumetric sampling rate which is usually required (Walton, 1954).

Another obvious possibility, the cyclone, is open to the objection that the dust is exposed to a process of attrition which may break down aggregates; moreover, the behaviour of a cyclone is critically dependent on its design.

Recently Walton (1954) has investigated the whole question of elutriation and has shown that a simple horizontal elutriator has many practical advantages and is moreover capable of giving as sharp a cut-off as any other elutriation process. The process of separation it uses is closely similar to that occurring in the respiratory tract, and although the shape of the cut-off curve is somewhat different from that currently attributed to the respiratory tract (Davies, 1952), the difference is not great and, owing to the general constancy of size distribution of dust particles in this size range (Wynn and Dawes, 1951), it is small in importance compared with the necessity of eliminating the bulk of the non-respirable dust.

The fundamental principle of a horizontal elutriator is that dusty air is passed through a horizontal duct at such a velocity that particles which it is desired to capture will settle on the floor of the duct before they reach the end. Particles of lower settling rate will, to a greater or lesser extent pass through the duct; those which were initially near the floor being captured, and those higher up passing through, the proportion doing so varying 
inversely as their settling rate, which in turn varies as the square of their diameter, for particles of the same shape and density. Thus if an elutriator is designed, as suggested by Hamilton and Walton (1952), to capture $50 \%$ of particles $5 \mu$ in diameter, it will capture only $2 \%$ of $1 \mu$ particles but will capture $100 \%$ of particles $7.07(5 \times \sqrt{2}) \mu$ in diameter. So long as the flow is streamline and not turbulent, the time taken by a particle of given settling velocity to fall from the top to the bottom of the duct will be proportional to the height of the duct ; and the time taken for the particle to traverse the length of the duct will be proportional to the air velocity. This in turn will be proportional to the volumetric flow-rate and the cross sectional area of the duct. If the height of the duct is increased, but its breadth kept constant, the time taken for a particle to fall from the top to the bottom will be increased, but the air velocity will be decreased proportionately, so the chance of a particle passing right through will not be affected. Thus, for a given volumetric flow rate the performance of a horizontal elutriator is independent of its height, and depends only on its length and breadth, i.e., the area of its floor. This area can be very easily calculated : if the volumetric flow through the elutriator is $Q$, and the terminal velocity of the largest particle which it is desired to capture $100 \%$ is $\mathrm{V}$ then the area of the floor required $=\frac{\mathrm{Q}}{\mathrm{V}}$.

The floor area can be arranged in any convenient way, either as a single long wide duct, or as a stack of shorter and narrower ones, so long as care is taken to ensure that flow will be streamline. When a stack of ducts is used attention must be paid to an important practical point which is not mentioned by Hamilton and Walton.

The flow through a flat horizontal duct at a given pressure depends on the cube of its height (Goldstein, 1938) and therefore some care is needed in its construction if it is made fairly shallow, which is desirable for the sake of compactness. For example, if the height of one duct is increased by $25 \%$ and the height of the adjacent duct decreased correspond-

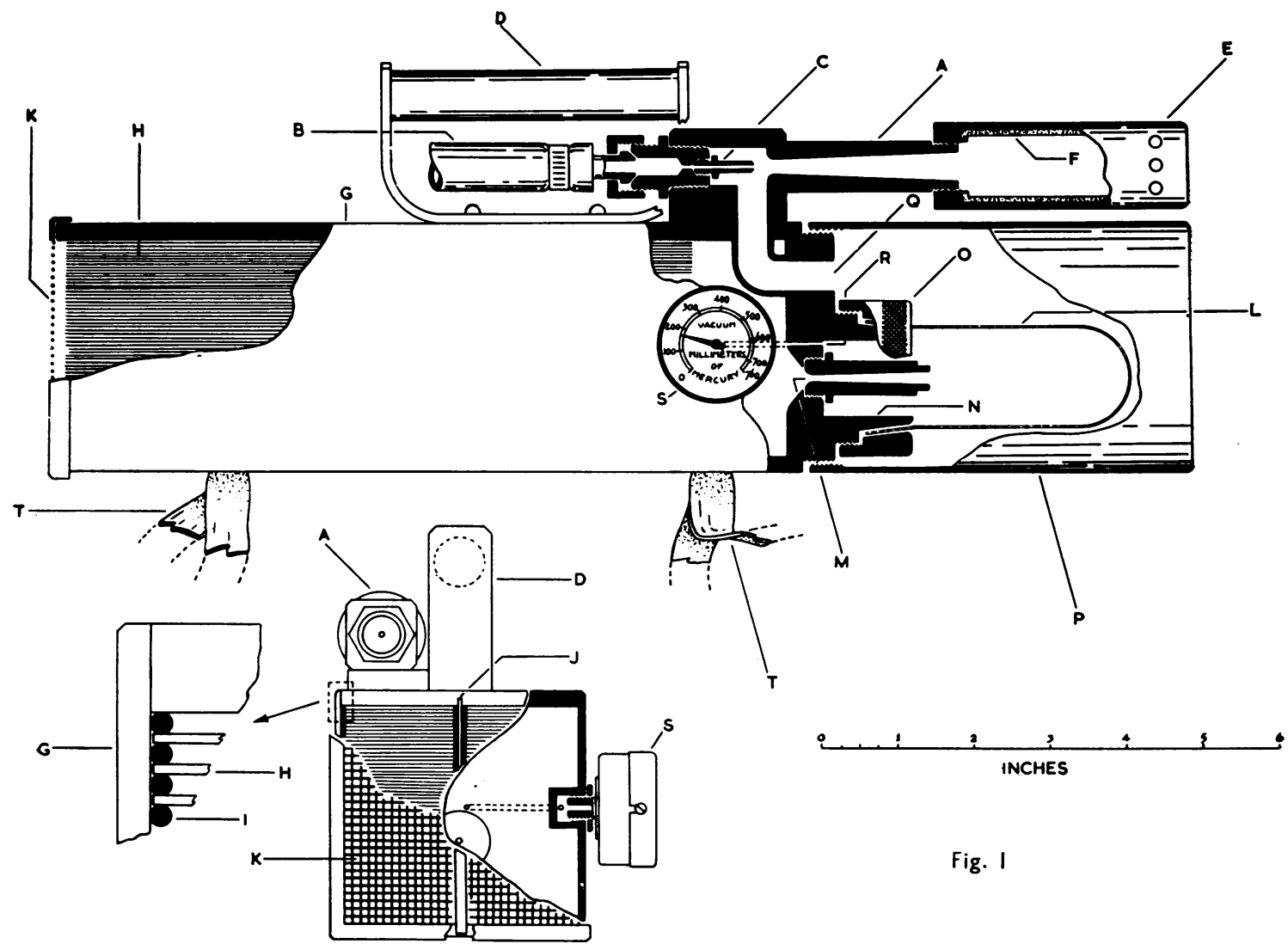


ingly, the flow through the former will be nearly doubled while that through the latter will be nearly halved, although the actual dimensional error in, for example, our model would be only 0.008 inches. The corresponding change in the cut-off will be from $7 \mu$ to about $10 \mu$ and $5 \mu$ respectively. The effect on the behaviour of the elutriator as a whole will, however, be greater than this, since there will also be a proportionate loss of finer particles in the shallower duct which cannot be balanced by a corresponding increased penetration through the other because penetration is already nearly $100 \%$.

In the instrument to be described, an elutriator of this type has been fitted to an improved form of the " soxhlet " thimble sampler described by Griffiths and Jones (1940).

\section{Description of Instrument}

The complete apparatus, which has been given the portmanteau name of "hexhlet", is shown diagrammatically in Fig. 1. It is made up of four components : the horizontal elutriator, a critical orifice to control the air flow, a "soxhlet" thimble for collecting dust, and a compressed air ejector to provide suction.

The elutriator consists of a rectangular box (G) made of aluminium alloy in which are stacked two banks of 58 aluminium plates (H) 0.020 in. $(0.5 \mathrm{~cm}$.) thick and 0.032 in. $(0.8 \mathrm{~cm}$.) apart separated by a partition $(\mathrm{J})$, forming 118 ducts. The plates are 1.42 in. $(3.55 \mathrm{~cm}$.) wide and $10.06 \mathrm{in} .(25.1 \mathrm{~cm}$.) long, so that the total floor area of the elutriator including the floor of the box between the end of the plates and the critical orifice is about 1,690 sq. in. $(10,903$ sq. $\mathrm{cm}$.).

The plates are separated by lengths of steel wire (I) as shown in the enlarged section, and the whole unit is assembled by stacking the plates and wires in a box and then clamping and screwing the top on. This method of construction (which was suggested by Mr. A. Hyett) gives excellent uniformity of duct height, and is at the same time much easier to carry out than the more obvious procedure of fitting the plates into slots in the side of the box. Ordinary rolled aluminium sheet is sufficiently flat for the purpose. Plastic sheet is unsuitable because of electrostatic effects.

The front end of the stack of plates is close to the end of the box and is protected by a stout wire mesh grid $(K)$. The rear end is about $1 \frac{1}{2}$ in. $(3.75 \mathrm{~cm}$.) from the end of the box, into which is fitted the critical orifice (M) leading to the inside of a "soxhlet" thimble (L). The purpose of this space is to prevent channelling of flow down the elutriator owing to undue proximity of some of the ducts to the orifice.

The vacuum gauge (S) which is connected to the inside of the "soxhlet" by the passage (R) enables the flow through the instrument to be checked at any time while in operation.

The " soxhlet " thimble is fitted on to a conical nozzle (N) to which it is secured by the knurled screw ring $(\mathrm{O})$, and is enclosed in a case (P) which is connected through the elbow connexion $(\mathrm{Q})$ to the air ejector $(\mathrm{A})$. The air from the latter passes into a silencer $(E)$ which is lined with felt (F).

The ejector is fitted with a short length of hose (B) which can be coiled up and secured with the two straps (T) so that the complete instrument can be carried by the handle (D) as shown in Fig. 2.

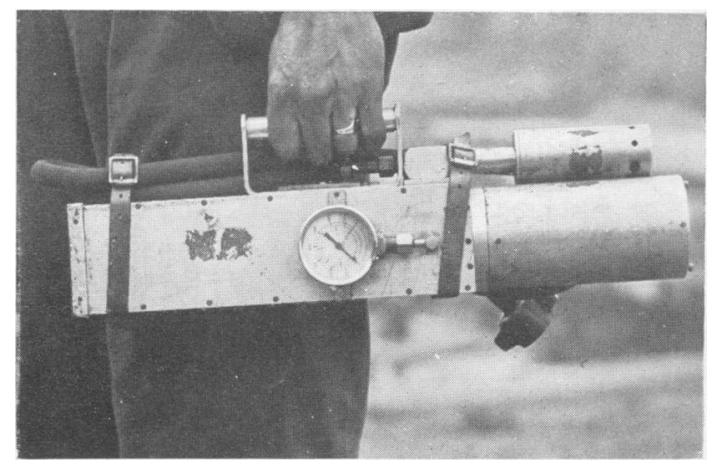

Fig. 2

\section{Performance}

The Elutriator.-The elutriator was designed to collect $50 \%$ of particles of unit density $5 \mu$ in diameter at a volumetric flow-rate of $1001 . / \mathrm{min}$. Its performance was checked by means of a cloud of monodisperse "pyrex" glass spheres of density 2.25 produced by feeding powdered " pyrex" glass by means of a dust feed mechanism (Wright, 1950) into the air supply of an air acetylene flame. The cloud consisted almost entirely of single spheres varying in size up to $15 \mu$ in diameter.

A preliminary test was carried out by placing glass cover slips at the front and rear ends of the plates at intervals all the way up the stack. This test showed good uniformity of cut-off and enabled a relative penetration curve to be constructed. In order to obtain an absolute penetration curve the following procedure was adopted (Fig. 3).

A hole $\frac{3}{8}$ in. in diameter was cut in the bottom of the case, between the end of the plates and the critical orifice, and was covered with a metal disc (U) about 2 in. in diameter, pivoted to one side of the hole.

A $\frac{3}{4}$ in. circular cover slip (V) was let into the upper surface of the disc, to one side of its centre, so that when the disc was suitably rotated the cover slip could be brought under the hole. Arrangements were made to block up the critical orifice inside the case $\mathbf{P}$ by means of a plunger (W) and $\operatorname{rod}(\mathrm{X})$ passing through the end of the case. In this way the space at the back of the elutriator case was turned into a sedimentation cell.

A sedimentation cell of the same height as the elutriator case was placed close to the front end of the instrument, and the whole assembly inserted in a 
chamber in which the cloud of spheres was being generated.

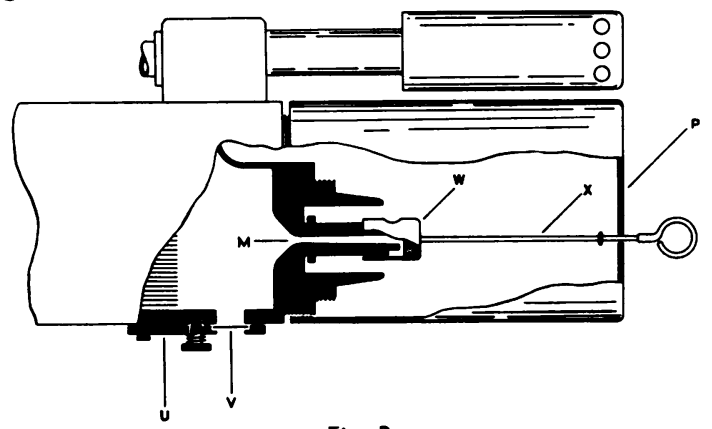

Fig. 3

The " hexhlet" was run for five minutes and then the flow was cut off sharply by means of the plunger (W), and at the same time the cover slips under the case and under the sedimentation cell were exposed. Time was allowed for spheres down to $0.5 \mu$ to settle and the process was repeated until examination of the " hexhlet" cover slip showed that a sufficiently dense deposit for counting had been obtained.

Total and differential counts were then made on the two samples, and the results combined to give the penetration curve shown in Fig. 4, where it is compared with the theoretical curve for a cut-off of $50 \%$ at $3 \cdot 3 \mu$ diameter for glass spheres (equivalent to $50 \%$ at $5 \mu$ for unit density).

The effect of loading the plates with coarse dust was determined by running the instrument in a heavy laboratory coal dust cloud, containing particles up to $100 \mu$ in diameter, until $2 \mathrm{~g}$. of " respirable" dust had collected in the filter. A subsequent test in the glass sphere cloud showed no change in the cut-off size. This is in conflict with the statement of Dawes (1954) ; the discrepancy may be due to the fact that in this model the ducts are so shallow that there is no possibility of turbulent flow being produced (Reynolds Number $=$ approximately 25 ).

The Critical Orifice.-The purpose of this is to maintain a constant volumetric flow-rate in spite of variations in compressed air pressure and the increasing resistance of the filter as dust is collected. Constancy of flow-rate is essential in order to maintain constancy of cut-off, and the use of a regulator and gauge such as that described by Watson and Morris (1952) would entail too much supervision.

The behaviour of a critical orifice is due to the fact that the flow through it depends only on the upstream pressure, and is independent of the downstream pressure, once the air velocity through the orifice reaches that of sound (Hartshorn, 1918). In a vacuum system such as this the upstream pressure is atmospheric and therefore substantially constant in a given place. It is, however, necessary that the orifice should be upstream of any source of varying resistance in the system, which in this case is the filter, so all the dust collected has to pass through the orifice. Since this dust is all of very fine particle size it has almost no abrasive power and does not wear the orifice appreciably, nor does blockage occur. The disadvantage of a critical orifice is that it consumes a good deal of power (about $\frac{1}{10}$ h.p. in this instrument). At the suggestion of Dr. C. N. Davies the orifice was therefore fitted with a tapered outlet which gives a substantial recovery of pressure head (Hartshorn, 1918), so that critical flow is obtained with only $100 \mathrm{~mm}$. of vacuum, instead of the more usual $350 \mathrm{~mm}$. (Perry, 1941). The diameter of the orifice was calculated from the formula given by Perry (1941) for a flow of $1001 . / \mathrm{min}$. The orifice was then drilled a little undersize $(0 \cdot 14 \mathrm{in}$.) and reamed out until it gave the correct flow. Clogging of the filter or lack of air pressure is indicated by the vacuum gauge ; if the vacuum falls

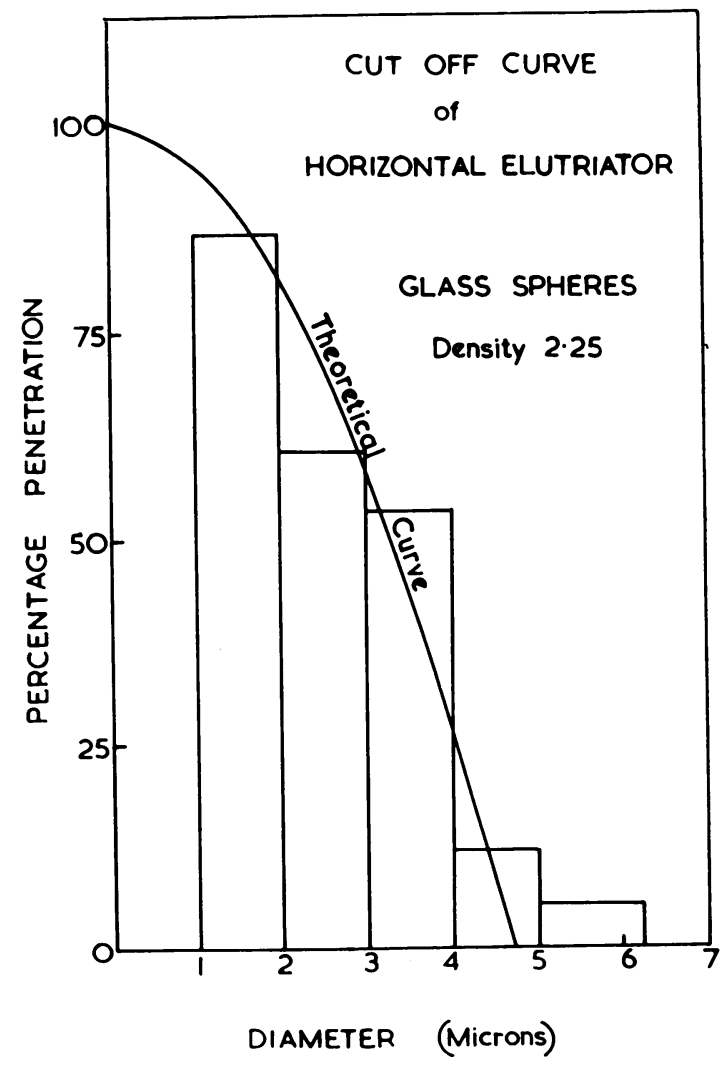

Fig. 4 
below $100 \mathrm{~mm}$. $\mathrm{Hg}$ with an adequate air pressure, the filter must be changed or the cake of dust dislodged.

Up to $1 \mathrm{~g}$. of " respirable" dust can usually be collected in the filter before this is necessary.

The Soxhlet Filter.-As pointed out by Watson and Morris (1952), about $100 \mathrm{mg}$. of dust is permanently trapped in the filter, whose resistance is thereby also permanently raised. The loss of dust might be materially reduced by " pre-clogging" the filter with a suitable inert dust.

The Air Ejector.-This is similar in design to that used by Watson and Morris but the jet (C) is only $\frac{3}{32} \mathrm{in}$. in diameter and the rest of the device is scaled down accordingly. The best position of the jet in relation to the throat was determined by experiment. The ejector will give a critical flow at $1001 . / \mathrm{min}$. through a clean "soxhlet" filter with a compressed air pressure of $25 \mathrm{lb}$. per sq. in. or more. As most compressed air supplies give a pressure of $60 \mathrm{lb}$. per sq. in. or more there is ample margin to allow for the build-up of dust on the filter.

Coal dust is collected at a rate of about $1 \mathrm{~g}$. in an eight-hour shift at an average concentration of 850 particles $/ \mathrm{ml} .(1 \cdot 0-5 \cdot 0 \mu)$.

The felt-lined silencer has a striking effect in reducing the otherwise very offensive noise made by the ejector.

The instrument in its final form has now been in routine use in this Unit for six months, and has given satisfactory results. Its weight of $10 \mathrm{lb}$. makes it reasonably portable, but the need for a compressed air supply limits its range of usefulness. Where compressed air is not available an electric vacuum pump can be used, though, owing to the resistance of the critical orifice and the filter, a pump of about $\frac{1}{3}$ h.p. is required. For use in this way, the silencer is removed and the vacuum pipe connected to the outlet of the ejector, the inlet being closed by means of a blanking nut instead of the hose connexion.

In a mine the instrument is usually hung from the roof by cords, but any convenient method of support is satisfactory so long as care is taken to keep it reasonably nearly horizontal. The effect of deviation from the horizontal is to decrease the effective settling rate of the particles on to the plates, and therefore increase the cut-off size. This effect is small, since it depends on the square root of the cosine of the angle of deviation from the horizontal. An angle of $5^{\circ}$ (which is easily appreciated) produces an increase in cut-off size of only $\frac{1}{5} \%$.

The instrument tends to build up a static charge, so it is essential to earth it by means of a metallic connexion to a water or compressed air pipe.

\section{Summary}

The composition of airborne dust is liable to vary with particle size.

Only particles less than about $7 \mu$ in average diameter are retained in the lungs long enough to cause pneumoconiosis. Samples of airborne dust for analysis in connexion with pneumoconiosis must therefore be free of particles larger than this. The separation of these particles should be carried out during the process of sampling.

An apparatus for collecting bulk samples of airborne dust is described in which a horizontal elutriator is used to separate off the oversize fraction while sampling, the " respirable" fraction being collected in a "soxhlet" thimble filter. A compressed air ejector is used to draw air through the sampler, and a critical orifice controls the flow.

The theoretical principles on which the design of the sampler is based are discussed, and the method of testing its performance is described.

The instrument was developed and the first model made in this laboratory and is the combined product of many workers to whom I am much indebted. Thanks are due especially to Mr. W. H. Walton and Mr. R. J. Hamilton, of the National Coal Board's Central Research Establishment, for advice on the design of the elutriator. The final model was constructed by Mr. V. Gubb and the tests of the elutriator and critical orifice carried out by Mr. N. E. Bevan. Mr. H. S. Wolff designed the silencer, and also suggested the name "hexhlet". Mr. W. H. Roberts prepared the drawings.

Messrs. C. F. Casella \& Co. Ltd., Regent House, Fitzroy Square, London, W.1, will be the makers.

\section{REFERENCES}

Davies, C. N. (1949). British Journal of Industrial Medicine, 6, 245. (1952). Ibid., 9, 120

Dawes, J. G. (1954). Contribution to discussion on paper by Walton, W. H., Proc. Conf. on the Physics of Particle Size Analysis ; Inst of Physics. Suppl. To be published.

Drinker, P., and Hatch, T. (1936). Industrial Dust, p. 162. McGrawHill, New York.

Findeisen, W. (1935). Pfügers Arch. ges. Physiol., 236, 367.

Goldstein, S. (1938). Modern Developments in Fluid Dvnamics. Vol. 1. (Oxford University Press, London.

Griffiths, J. H., and Jones, T. D. (1940). Trans. Instn. Min. Engrs, 99, 150 .

Hamilton, R. J., and Walton, W. H. (1952). The Selective Sampling of Airborne Dust. National Coal Board, Scientific Department. Central Research Establishment. Rep. No. 139.

Hartshorn, L. (1918). Proc. roy. Soc. A., 94, 155.

Haultain, H. E. T. (1937). Trans. Canad. Inst. Min. Metall. and of Mining Soc. Nova Scotia, 40, 229.

McCrae, J. (1913). S. Afr. Inst. med. Res. Publ., "The Ash of Silicotic Lungs." Afr. Inst.

Perry, J. H. (1941). Chemical Engineers' Handbook, 2nd ed., p. 847. McGraw-Hill, New York.

Walton, W. H. (1954). Proc. Conf. on the Physics of Particle Size Analysis ; Inst. of Physics. Suppl. To be published.

Watkins-Pitchford, W. (1916). General Report of the Miners' Phthisis Prevention Committee, Pretoria, Appendix 8, pp 135-138.

Watson, H. H. (1949). Proc. 9th Int. Conf. Indust. Med., London, p. 211. Wright, Bristol (Lond.).

Tra and Morris, T. G. (1952). Engineering, 174, 228.

Wynn, A. H. A., and Dawes, J. G. (1951). Min. Fuel and Power S.M.R.E.' Res. Rep. No. 28. 